\title{
Um panorama da epistemologia de Ludwik Fleck em periódicos brasileiros da área de pesquisa em ensino de ciências
}

\author{
An overview of the Ludwik Fleck's epistemology in Brazilian journals of \\ science education research area
}

\begin{abstract}
Una visión general de la epistemología de Ludwik Fleck en las revistas brasileñas del área de investigación en la enseñanza de las ciencias
\end{abstract}

\author{
Beatriz Aparecida de Souza (beatriz.souzafr@gmail.com) \\ Universidade Federal do Rio Grande do Norte-UFRN. \\ André Ferrer Pinto Martins (aferrer34@yahoo.com.br) \\ Universidade Federal do Rio Grande do Norte-UFRN
}

Resumo: Este artigo apresenta um panorama dos trabalhos em periódicos que empregam a epistemologia de Ludwik Fleck (1896 - 1961) como referencial teórico. Caracteriza-se como uma pesquisa bibliográfica. Foi realizado um levantamento dos trabalhos publicados em periódicos brasileiros da área de ensino de ciências (Qualis A1, A2 e B1) no período de 2001 a 2020, encontrando-se um total de 32 artigos publicados no decorrer dos últimos vinte anos. $\mathrm{Na}$ análise dos artigos procurou-se identificar as terminologias utilizadas para se referir aos conceitos fleckianos, bem como as descrições desses conceitos, observando-se diferenças e aproximações nos entendimentos apresentados pelos artigos. Foi identificado que os conceitos mais abordados foram: estilo de pensamento, coletivo de pensamento, círculos esotérico e exotérico, circulação intracoletiva e intercoletiva. Os conceitos de conexões ativas e passivas estão menos presentes. Identificou-se, também, o uso de diferentes terminologias para os conceitos de circulação de ideias e conexões e a presença de variações no entendimento acerca das categorias circulação intracoletiva e intercoletiva.

Palavras-chave: Ludwik Fleck; Epistemologia; Ensino de ciência.

Abstract: This article presents an overview of the works in journals that use the epistemology of Ludwik Fleck (1896 - 1961) as a theoretical framework. It is characterized as a bibliographic search. A survey of works published in Brazilian journals in the field of science education (Qualis A1, A2 and B1) was conducted from 2001 to 2020, finding a total of 32 articles published over the last twenty years. In the analysis of the articles, we sought to identify the terminologies used to refer to Fleckian concepts, as well as the descriptions of these concepts, observing differences and similarities in the understandings presented by the articles. It was identified that the most discussed concepts were: thought style, thought collective, esoteric and exoteric

Recebido em: 10/02/2021

Aceite em: $11 / 08 / 2021$ 
circles, intracollective and intercollective circulation. The concepts of active and passive connections are less present. It was also identified the use of different terminologies for the concepts of circulation of ideas and connections and the presence of variations in the understanding of the categories intracollective and intercollective circulation.

Keywords: Ludwik Fleck; epistemology; science education.

Resumen: Este artículo presenta una visión general de los trabajos en revistas que utilizan la epistemología de Ludwik Fleck (1896 - 1961) como marco teórico. Se caracteriza por ser una búsqueda bibliográfica. Se realizó una encuesta de trabajos publicados en revistas brasileñas en el campo de la educación científica (Qualis A1, A2 y B1) entre 2001 y 2020, encontrando un total de 32 artículos publicados en los últimos veinte años. En el análisis de los artículos se buscó identificar las terminologías utilizadas para referirse a los conceptos fleckianos, así como las descripciones de estos conceptos, observando diferencias y similitudes en los entendimientos presentados por los artículos. Se identificó que los conceptos más discutidos fueron: estilo de pensamiento, colectivo de pensamiento, círculos esotéricos y exotéricos, circulación intracolectiva e intercolectiva. Los conceptos de conexiones activas y pasivas están menos presentes. También se identificó el uso de diferentes terminologías para los conceptos de circulación de ideas y conexiones y la presencia de variaciones en la comprensión de las categorías circulación intracolectiva e intercolectiva.

Palabras-clave: Ludwik Fleck; Epistemología; Enseñanza de la ciencia.

\section{INTRODUÇÃO}

Ludwik Fleck (1896 - 1961) foi um médico e microbiologista judeu, nascido em Lwów, na Polônia, cidade que hoje pertence à Ucrânia. Em sua principal obra, Gênese e Desenvolvimento de um Fato Científico (original de 1935), Fleck descreve a história do conceito da sífilis e do desenvolvimento da reação de Wassermann, e, a partir da análise desses dois exemplos, elabora a sua epistemologia, partindo do princípio de que o conhecimento científico é coletivo, condicionado histórica e socialmente (COHEN; SCHNELLE, 1986). No decorrer do livro, Fleck forja diversos conceitos que auxiliam na sua análise da ciência e do conhecimento em geral. Dentre os principais estão: estilo de pensamento $(\mathrm{EP})^{1}$, coletivo de pensamento $(\mathrm{CP})$, círculos esotérico e exotérico, circulação intracoletiva e intercoletiva, conexões ativas e passivas ${ }^{2}$.

\footnotetext{
${ }^{1}$ Em particular, 'estilo de pensamento' (Denkstil) é um conceito introduzido na língua alemã por Karl Mannheim, na década de 1920.

2 Nosso trabalho não tenciona apresentar a biografia de Fleck nem sua epistemologia. Para dados biográficos desse autor, recomendamos a leitura da Introdução de Fleck (2010) e a Parte I de Cohen e Recebido em: 10/02/2021
}

Aceite em: $11 / 08 / 2021$ 
O livro Gênese e Desenvolvimento de um Fato Científico foi publicado originalmente em alemão, uma vez que essa era uma das principais línguas para a divulgação científica, à época. No entanto, o crescente antissemitismo na Europa tornou impraticável a publicação da obra na Polônia, o que teria levado Fleck a buscar uma editora na Suíça. A tiragem foi de cerca de 600 exemplares, com apenas 200 cópias vendidas (TRENN, 1979). Nesse cenário, a sua obra permaneceu quase totalmente desconhecida, restrita a poucas resenhas em revistas da área médica (COHEN; SCHNELLE, 1986).

Foi apenas em 1962, com a publicação do aclamado livro A Estrutura das Revoluções Científicas, de Thomas Kuhn, no qual o trabalho de Fleck é mencionado no prefácio, que a sua obra começou a ser resgatada. A epistemologia fleckiana alcançou maior repercussão com a tradução do seu livro para o inglês em 1979 e a ocorrência de dois encontros científicos em sua homenagem, o primeiro realizado em 1981, organizado por Lothar Schäfer e Thomas Schnelle, e o segundo, em 1984, planejado por Robert Cohen (COHEN; SCHNELLE, 1986). Outro evento que contribuiu para a divulgação do pensamento de Fleck foi a publicação do livro Cognition and Fact (1986), que resultou dos encontros acima mencionados e traz os artigos produzidos por Fleck no ramo da filosofia da ciência, assim como trabalhos de outros comentadores da sua obra.

Desde então, a sua obra tem sido bastante disseminada por meio das traduções do seu livro para vários idiomas, como italiano (1983), espanhol (1986), polonês (1986), francês (2005) e, mais recentemente, para o português, no ano de 2010. O processo de tradução do livro de Fleck se revelou uma tarefa delicada. Trenn (1979), tradutor da obra para a língua inglesa, exprime que o manuscrito original é complexo e frequentemente idiossincrático, enquanto os tradutores da obra para o português mencionam desafios com termos teóricos, neologismos e arcaísmos (LANG, 2016), por exemplo.

Nesse contexto de divulgação da sua obra, o pensamento fleckiano ganhou notoriedade, passando a figurar como referencial teórico de trabalhos para além da área da saúde e da história da medicina, como, por exemplo, no campo da história e filosofia

Schnelle (1986). Quanto à epistemologia, indicamos sua obra principal (FLECK, 2010) e seus sete artigos presentes na Parte II de Cohen e Schnelle (1986).

Recebido em: 10/02/2021

Aceite em: $11 / 08 / 2021$ 
da ciência e na área de ensino de ciências. Sobre essa última, Martins (2020a, p. 1215) argumenta que:

[...] a perspectiva fleckiana permite um novo olhar sobre esse gigantesco empreendimento coletivo que é a educação. Enquanto processo de constituição e manutenção de coletivos e respectivos estilos de pensamento, as dinâmicas tanto da educação escolar formal quanto da educação não-formal e informal, bem como o aprendizado e a "iniciação" numa determinada área do saber, têm muito a ganhar com o olhar da sociologia de Fleck, que propicia frutíferas categorias teóricas de análise e interpretação.

No Brasil, as categorias epistemológicas fleckianas vêm sendo utilizadas consistentemente na pesquisa em ensino de ciências. Lorenzetti, Muenchen e Slongo (2013) investigaram a presença da epistemologia fleckiana em pesquisas em Educação em Ciências, entre teses e dissertações, publicadas nos anos de 1995 a 2010. Como resultado, os autores encontraram um total de 13 trabalhos, bem como a predominância na utilização dos conceitos estilo de pensamento, coletivo de pensamento, circulação intra e intercoletiva. Em um artigo mais recente, Lorenzetti, Muenchen e Slongo (2018) realizaram uma pesquisa semelhante, ampliando a cobertura dos anos para o período compreendido entre 1995 e 2015. Os autores identificaram um crescimento de trabalhos que utilizam o referencial teórico de Fleck, somando ao todo 37 pesquisas $^{3}$, o que significa um aumento de 24 trabalhos no período de cinco anos.

Chicóra, Aires e Camargo (2018) também investigaram a presença da epistemologia de Fleck como referencial teórico em pesquisas em Educação em Ciências. A pesquisa se ateve a trabalhos publicados em atas do Encontro Nacional de Pesquisa em Educação em Ciências, evento nacional promovido pela Associação Brasileira de Pesquisa em Educação em Ciências, que possui grande destaque quanto à divulgação de pesquisas em Ensino de Ciências (SILVEIRA; MIRANDA, 2019; OLIVEIRA et al., 2021). Os autores localizaram 16 trabalhos publicados, no período de 1997 a 2015, destacando o predomínio no uso dos conceitos estilo de pensamento, coletivo de pensamento, circulação intra e intercoletiva.

Considerando que as revisões citadas no parágrafo anterior abarcam dissertações, teses e trabalhos em evento, existe uma lacuna na literatura da área com relação a

\footnotetext{
${ }^{3} \mathrm{O}$ estudo recolheu um total de 89 trabalhos, dos quais 37 inserem-se na área de pesquisa em ensino de ciências.
}

Recebido em: 10/02/2021

Aceite em: $11 / 08 / 2021$ 
artigos em periódicos. Nessa direção, objetivamos, nesse estudo, realizar uma revisão da literatura dos artigos que empregam a epistemologia de Ludwik Fleck como referencial teórico, publicados em periódicos da área de ensino de ciências no período de 2001 a 2020. Assim como em Lorenzetti, Muenchen e Slongo (2013, 2018) e Chicóra, Aires e Camargo (2018), identificamos o uso de conceitos de Fleck, mas, diferentemente desses outros estudos, propusemo-nos, também, a analisar como os conceitos propostos por Fleck estão sendo abordados, identificando variações e tendências na terminologia adotada e na compreensão dos conceitos nos diversos trabalhos.

\section{PROCEDIMENTOS METODOLÓGICOS E PANORAMA INICIAL}

O presente estudo se configura como uma revisão bibliográfica. Segundo Marconi e Lakatos (2002, p. 25):

A pesquisa bibliográfica é um apanhado geral sobre os principais trabalhos já realizados, revestidos de importância por serem capazes de fornecer dados atuais e relevantes relacionados com o tema. $\mathrm{O}$ estudo da literatura pertinente pode ajudar a planificação do trabalho, evitar duplicações e certos erros, e representa uma fonte indispensável de informações podendo até orientar as indagações.

Ainda de acordo com Marconi e Lakatos (2002, p. 71) a "pesquisa bibliográfica não é mera repetição do que já foi dito ou escrito sobre certo assunto, mas propicia o exame de um tema sob novo enfoque ou abordagem, chegando a conclusões inovadoras".

Nesse sentido, fizemos o levantamento dos artigos publicados nos periódicos nacionais da área de Ensino conceituados como Qualis A1, A2 e B1 pela Coordenação de Aperfeiçoamento de Pessoal de Nível Superior (CAPES) no quadriênio de 20132016.

Selecionamos os periódicos de acordo com as descrições contidas no foco e escopo das revistas, incluindo apenas os que abrangiam a pesquisa na área de ensino de ciências. Para a localização dos trabalhos, utilizamos os termos 'Fleck' e 'Ludwik Fleck', os quais foram pesquisados nos títulos, resumos e palavras-chave dos artigos. $\mathrm{O}$ recorte temporal para esse estudo foi de 2001 a 2020, a fim de contemplar as duas últimas décadas de produção acadêmica na área.

Recebido em: 10/02/2021

Aceite em: $11 / 08 / 2021$ 
Em seguida, em uma primeira aproximação, realizamos a leitura dos resumos dos artigos, com o intuito de identificar a sua pertinência, selecionando os que se adequavam ao objetivo do nosso trabalho. Encontramos 32 artigos que utilizaram a epistemologia de Fleck como referencial teórico ${ }^{4}$. Na Tabela 1 expomos o levantamento do número de artigos por periódico, acompanhados dos respectivos Qualis (2013-2016). Os artigos encontrados estão distribuídos em dez revistas. O maior número de artigos publicados foi encontrado nas revistas Investigações em Ensino de Ciências e Revista Brasileira de Pesquisa em Educação em Ciências, ambas com 7 artigos.

Tabela 1 - Levantamento do número de artigos por periódico.

\begin{tabular}{c|c|c}
\hline Periódico & Qualis & N $^{\circ}$ de artigos \\
\hline Ensaio Pesquisa em Educação em Ciências & A1 & 4 \\
\hline Ciência \& educação & A1 & 2 \\
\hline Investigações em Ensino de Ciências & A2 & 7 \\
\hline Revista Brasileira de Pesquisa em Educação em Ciências & A2 & 7 \\
\hline Alexandria & A2 & 3 \\
\hline Caderno Brasileiro de Ensino de Física & A2 & 3 \\
\hline Areté | Revista Amazônica de Ensino de Ciências & A2 & 2 \\
\hline Revista Brasileira de Ensino de Ciência e Tecnologia & A2 & 2 \\
\hline Ensino de Ciências e Tecnologia em Revista & B1 & 1 \\
\hline Química Nova na Escola & B1 & 1 \\
\hline TOTAL & - & 32 \\
\hline
\end{tabular}

Apesar de estabelecermos o recorte de 20 anos, encontramos a primeira publicação em 2002. Na Figura 1 apresentamos o levantamento do número de artigos publicados por ano, onde é possível observar que, entre 2001 e 2010, foram publicados

\footnotetext{
${ }^{4}$ A lista completa dos artigos não foi colocada nas referências por questões de limitação de espaço, mas pode ser acessada por um link que se encontra no Anexo. Nas referências constam apenas aqueles trabalhos citados explicitamente ao longo do nosso estudo.
}

Recebido em: 10/02/2021

Aceite em: $11 / 08 / 2021$ 
9 artigos, enquanto a partir de 2011 ocorreu um aumento no número de publicações, totalizando 23 artigos.

Após a leitura inicial, realizamos a leitura na íntegra dos artigos selecionados, procurando identificar: 1) os conceitos fleckianos mencionados nos artigos, observando quais terminologias eram utilizadas para se referir a esses conceitos; 2) os conceitos fleckianos descritos - e não apenas mencionados - nos artigos, com o intuito de identificar a presença de diferentes entendimentos. As descrições dos conceitos encontradas nos artigos foram transcritas em uma planilha no Excel, juntamente com as informações do tipo de citação utilizada e do autor citado (caso houvesse citação). Em um segundo momento, separamos as descrições de cada conceito em cinco grupos, a saber: citação direta de Fleck (1986, 2010); citação indireta de Fleck (1986, 2010); citação direta de outros autores; citação indireta de outros autores; sem citação. Então, analisamos as descrições presentes nos grupos, observando diferenças e aproximações dentro de cada agrupamento e entre eles.

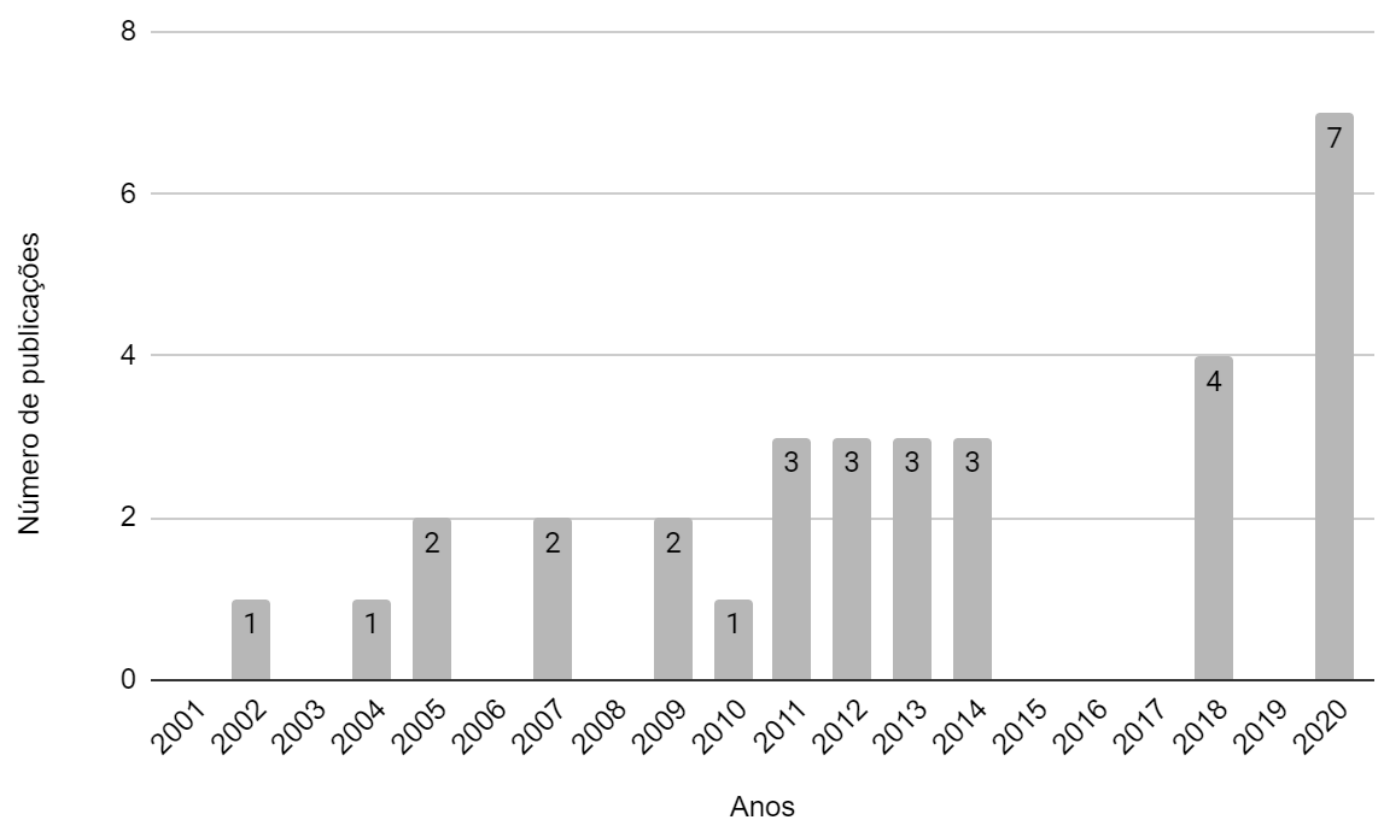

Figura 1 - Número de artigos publicados por ano. 


\section{RESULTADOS E DISCUSSÕES}

Os conceitos mais descritos (não apenas mencionados) nos trabalhos investigados na nossa pesquisa estão expostos na Tabela 2. Verificamos que estilo de pensamento e coletivo de pensamento são os que vêm em primeiro lugar, o que também é apontado por Lorenzetti, Muenchen e Slongo (2013, 2018) e Chicóra, Aires e Camargo (2018).

Tabela 2 - Levantamento dos conceitos de Fleck abordados nos artigos.

\begin{tabular}{c|c}
\hline Conceitos fleckianos* $^{*}$ & Número de artigos que os descrevem \\
\hline Estilo de pensamento & 30 \\
\hline Coletivo de pensamento & 29 \\
\hline Círculo esotérico & 26 \\
\hline Círculo exotérico & 25 \\
\hline Circulação intercoletiva & 23 \\
\hline Circulação intracoletiva & 19 \\
\hline Conexões passivas & 7 \\
\hline Conexões ativas & 7 \\
\hline
\end{tabular}

* Nessa lista não estão discriminadas as diferenças terminológicas.

\subsection{VARIAÇÕES NA TERMINOLOGIA UTILIZADA}

Nessa subseção, apresentamos as diferentes terminologias usadas para os conceitos fleckianos presentes nos artigos. Nessa análise, consideramos todas as menções aos conceitos feitas nos artigos e não apenas a presença de descrições dos mesmos. Identificamos variações terminológicas para os conceitos circulação de ideias e conexões.

Verificamos nos artigos a presença de dois termos para designar a circulação de ideias: o próprio termo 'circulação' e a palavra 'tráfego'. O uso da palavra 'circulação' foi observado em 31 dos 32 artigos, enquanto o termo 'tráfego' aparece em 8 artigos. Em 5 trabalhos o termo 'tráfego' surge apenas uma vez, através da citação direta de 
Fleck (2010, p. 161) “[...] qualquer tráfego intercoletivo de pensamentos traz consigo um deslocamento ou uma alteração dos valores de pensamento [...]”. Em 2 desses 6 artigos o seu uso apresenta-se mesclado no corpo do texto juntamente com o termo 'circulação'. E em 1 artigo ocorre apenas o termo 'tráfego', fazendo o autor referência ao fato da tradução para o português da obra de Fleck usar tal termo.

Observamos, ainda, outra variação quanto à terminologia usada para 'circulação'. Dentre os 31 artigos que usam o termo 'circulação de ideias', 10 artigos acrescentam um dos seguintes termos: 'práticas' ou 'métodos'. Um desses trabalhos, Delizoicov N., Carneiro e Delizoicov, D. (2004, p. 446), explica, em uma nota de rodapé, que "a designação 'circulação de idéias' é inadequada, uma vez que este processo de circulação, segundo o próprio Fleck (1986a), inclui disseminação de procedimentos e de práticas". A partir desses dados, observamos que a maioria dos autores, ao tratarem dos conceitos de circulação intracoletiva e intercoletiva, não evidenciam ou explicitam a circulação de práticas.

No que tange aos conceitos de conexões ativas e conexões passivas, constatamos dois usos, a saber: 'conexões ativas e passivas' e 'acoplamentos ativos e passivos'. Dos 7 artigos que descrevem esses conceitos, 3 trabalhos utilizam o termo 'conexões', enquanto outros três utilizam o termo 'acoplamento'. Um artigo utiliza o termo 'conexões' no corpo do texto, mas faz uso de uma citação de Fleck (2010) contendo o termo 'acoplamento'. Sobre isso os autores escrevem em uma nota de rodapé: "O livro de Fleck (2010) traduzido para o português traz o termo acoplamento, no entanto no decorrer do artigo utilizamos o termo conexões oriundo da tradução do seu livro em espanhol, Fleck (1986a). No presente texto os dois termos têm o mesmo significado" (QUEIRÓS; NARDI; DELIZOICOV, 2014, p. 107).

O uso das palavras 'tráfego' e 'acoplamento' têm sua primeira aparição na tradução para o português de Gênese e o Desenvolvimento de um Fato Científico, lançado no ano de 2010. Já os termos 'circulação' e 'conexões' estão presentes em artigos de todo o período anterior, provavelmente advindos de traduções dos próprios autores a partir da versão em espanhol do livro de Fleck (1986a), uma vez que todos os trabalhos prévios a 2010 usam-no como referência. Nessa tradução estão presentes os termos circulación e conexiones, para se referir à circulação de ideias e às conexões 
ativas e passivas, respectivamente. Apesar de a tradução do livro para o português ter introduzido novos termos, o uso de 'circulação' e ‘conexões' já havia se popularizado e, portanto, continuou figurando nos artigos após essa data.

A polêmica em torno das traduções dos conceitos elaborados por Fleck não é uma discussão local, mas algo presente em outros países. Evidência disso foi a promoção, em 2016, de uma conferência internacional realizada na Polônia, com foco na recepção mundial dos conceitos de Fleck e na discussão dos problemas e dificuldades de tradução da sua obra (LANG, 2016). Além disso, Cohen e Schnelle (1986) apontam que a tradução de certos termos da obra para o inglês é imprecisa, entre os quais, os autores mencionam Koppelungen, que foi traduzido para o inglês como connections e associations. Essas palavras, quando traduzidas para o português, correspondem a conexões e associações. Os autores sugerem que uma tradução mais adequada seria couplings (em português: “acoplamentos”), termo que é utilizado na obra em língua portuguesa.

\subsection{DESCRIÇÕES DOS CONCEITOS}

Nessa subseção expomos e discutimos o modo como os trabalhos apresentam os conceitos fleckianos mostrados na Tabela 2.

Em relação ao conceito de estilo de pensamento, descrito em 30 artigos, observamos que 16 artigos citam diretamente o seguinte trecho de Fleck: "percepção direcionada em conjunção com o processamento correspondente no plano mental e objetivo" (2010, p. 149) ou traduções realizadas pelos próprios autores do seguinte trecho da versão do livro em espanhol: "percibir dirigido con la correspondiente elaboracíon intelectiva y objetiva de lo percibido" (1986a, p. 145). Enquanto 14 artigos citam Fleck (1986a, 2010) indiretamente, no que parece ser uma interpretação do mesmo trecho de Fleck citado acima. Trazemos como exemplo Lambach e Marques (2014a, p. 87): "um direcionamento do olhar que orienta sua prática e guia o que observar, o que olhar e como olhar”. Dentre os 30 artigos, 7 complementam a descrição indicando um conjunto de atributos que caracterizam o EP. Como exemplo citamos o seguinte trecho: "A categoria Estilo de Pensamento comporta de modo estruturado uma visão de mundo, um sistema fechado de crenças, um corpo de conhecimento que, além Recebido em: 10/02/2021 
de elementos teóricos, caracteriza-se por uma linguagem própria e práticas específicas" (DELIZOICOV, N.; CARNEIRO; DELIZOICOV, D., 2004, p. 445).

Observamos que não parece haver divergências na compreensão acerca do conceito de estilo de pensamento nos artigos analisados. Essa homogeneidade se dá, aparentemente, em função da abordagem do próprio Fleck a esse respeito, que expõe claramente:

Podemos, portanto, definir o estilo de pensamento como percepção direcionada em conjunção com o processamento correspondente no plano mental e objetivo. Esse estilo é marcado por características comuns dos problemas, que interessam a um coletivo de pensamento; dos julgamentos, que considera como evidentes e dos métodos, que aplica como meios do conhecimento. É acompanhado, eventualmente, por um estilo técnico e literário do sistema do saber (FLECK, 2010, p. 149, grifos do autor).

Quanto ao conceito de coletivo de pensamento, o qual 29 artigos apresentam descrições, identificamos que 9 artigos citam diretamente o seguinte trecho de Fleck (2010, p. 82): “comunidade de pessoas que trocam pensamentos ou se encontram numa situação de influência recíproca de pensamentos" (FLECK, 2010, p. 82, grifos do autor). Outros 17 artigos citam Fleck (1986a, 2010) indiretamente, definindo o CP como indivíduos que compartilham determinadas práticas, concepções, tradições, normas e linguagens, em outros termos, um estilo de pensamento. Além desses, 3 artigos citam outros autores ao definir o CP. É o caso de Muenchen e Delizoicov (2011, p. 86, 2012, p. 202), que citam diretamente Leite et al. (2001, não paginado) "comunidade de indivíduos que compartilham práticas, concepções, tradições e normas" e Flôr (2009, p. 248), que cita indiretamente Scheid, Ferrari, e Delizoicov (2005) "uma comunidade de indivíduos que compartilham práticas, concepções, tradições e normas".

Os exemplos citados acima revelam que há uma consonância quanto ao entendimento desse conceito, seja através de citações diretas ou indiretas. Os artigos transmitem, essencialmente, a mesma informação, que é originalmente encontrada na seguinte forma:

Se definirmos o "coletivo de pensamento" como a comunidade das pessoas que trocam pensamentos ou se encontram numa situação de influência recíproca de pensamentos, temos, em cada uma dessas pessoas, um portador do desenvolvimento histórico de uma área de pensamento, de um determinado estado do saber e da cultura, ou seja, de um estilo específico de pensamento. Assim, o coletivo de pensamento representa o elo que faltava na relação que procuramos (FLECK, 2010, p. 82, grifos do autor).

Recebido em: 10/02/2021

Aceite em: $11 / 08 / 2021$ 
Ainda a respeito de coletivo de pensamento, Fleck (2010, p. 157) explica que:

\begin{abstract}
Essa estrutura universal do coletivo de pensamento consiste no seguinte: em torno de qualquer formação do pensamento, seja um dogma religioso, uma ideia científica ou um pensamento artístico, forma-se um pequeno círculo esotérico e um círculo exotérico maior de participantes do coletivo de pensamento.
\end{abstract}

Entre os trabalhos investigados por esta pesquisa, o conceito de círculo esotérico está presente em 26 artigos, enquanto círculo exotérico aparece em 25.

Acerca do conceito de círculo esotérico, 24 artigos citam Fleck (1986 a 2010) indiretamente, descrevendo o círculo esotérico como o grupo de especialistas de uma determinada área. Enquanto isso, 2 artigos citam outros autores: Tomio e Cassiani (2013, p. 271) citam diretamente Slongo e Delizoicov (2006, p. 334): “Círculos esotéricos - constituídos por investigadores que produzem conhecimentos inéditos" e Delizoicov et al. (2002, p. 60) citam diretamente Schäfer e Schnelle (1986, p. 32): “A delimitação pelos especialistas de um campo de problemas dentro da generalidade científica”.

$\mathrm{Na}$ descrição de círculo exotérico, observamos que 20 dos 25 artigos citam Fleck (1986a, 2010) indiretamente, definindo o círculo exo como os indivíduos nãoespecialistas, leigos ou leigos formados. Desses, 6 artigos evidenciam o caráter relativo da relação, como mostra Milaré e Rezende (2018, p. 311): “[...] um grupo pode ser caracterizado como círculo exotérico em relação a um determinado conhecimento, mas, esotérico em relação à outra área de conhecimento".

Outros 5 artigos descrevem o círculo exotérico como sendo constituído por indivíduos que consomem o conhecimento produzido pelo círculo esotérico. Por exemplo, Flôr (2009, p. 248), que cita Scheid, Ferrari e Delizoicov (2005) indiretamente: "Os coletivos de pensamento estratificam-se em círculos: o exotérico e o esotérico. O primeiro é entendido como sendo constituído pelos indivíduos que, de uma forma ou de outra, consomem o conhecimento produzido pelo segundo".

A partir do que foi exposto sobre os círculos esotérico e exotérico, observamos que as definições são convergentes: no círculo esotérico estão os especialistas, ou seja, os produtores de conhecimento de um dado coletivo, enquanto no círculo exotérico encontram-se os não-especialistas, os leigos, isto é, os indivíduos que compartilham do 
estilo de pensamento do coletivo, mas que não estão diretamente relacionados com a produção desse.

O conceito de circulação intracoletiva foi identificado em 19 trabalhos, dos quais 14 o descrevem como uma comunicação entre os membros de um mesmo coletivo, sem haver referência aos círculos eso e exo. 2 artigos descrevem circulação intracoletiva como uma circulação entre os círculos esotérico e exotérico de um mesmo coletivo, por exemplo, Magoga e Muenchen (2018, p. 138) escrevem: "dentro de um CP ocorre comunicações internas, entre os sujeitos do círculo 'eso' e 'exo' através da chamada circulação intracoletiva de ideias". Por fim, outros 3 artigos descrevem a circulação intracoletiva como uma comunicação apenas entre os integrantes do círculo esotérico, como apontado por Queirós, Nardi e Delizoicov (2014, p. 101):

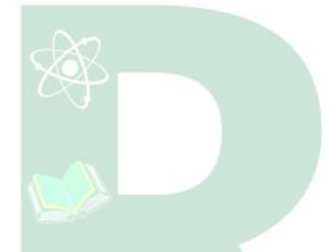

A interação entre os círculos esotéricos e exotéricos ocorre, respectivamente, através da circulação intracoletiva e intercoletivas de ideias e práticas. A primeira acontece quando especialistas de um mesmo círculo compartilham entre si o seu EP; a segunda, por sua vez, quando há interação entre coletivos com EPs distintos.

O conceito de circulação intercoletiva está presente em 23 artigos. 16 trabalhos a descrevem como uma comunicação que ocorre entre coletivos distintos, por exemplo, Flôr (2009, p. 247) coloca: "O que Fleck chama de circulação intercoletiva de ideias, que acontece quando cientistas portadores de diferentes estilos de pensamento tomam conhecimento dos desenvolvimentos científicos de outras áreas". Ao passo que 6 artigos descrevem a circulação intercoletiva como uma comunicação entre os círculos esotérico e exotérico, como defendem Gonçalves, Marques e Delizoicov (2007, não paginado):

\footnotetext{
A dinâmica de circulação intercoletiva de ideias, proposta por Fleck (1986), auxilia a compreender a interação entre o círculo esotérico e exotérico. Para o epistemólogo, a intensidade da circulação intercoletiva de idéias está relacionada com as possíveis diferenças entre os estilos de pensamento de cada coletivo.
}

Outro exemplo desse entendimento é encontrado em Gonçalves e Marques (2012b, p. 184), que cita diretamente Delizoicov (2004, p.166): “[...] é a circulação intercoletiva de idéias a responsável pela disseminação, popularização e vulgarização do(s) estilos(s) de pensamento para outros coletivos de não-especialistas, que constituem, para Fleck, círculos exotéricos relativamente a um determinado círculo esotérico". Em Lambach e Marques (2014b, p. 12) observamos uma compreensão 
semelhante: "Já na disseminação do EP do círculo Eso para os círculos Exo, ocorre a Circulação Intercoletiva de Ideias, que pressupõe introdução de novas ideias de um CP em outro com seu EP instaurado participantes de um coletivo de pensamento que não seja o mesmo do esotérico".

Por fim, 1 artigo descreve a circulação intercoletiva como uma circulação de ideias entre indivíduos de um mesmo círculo esotérico. De acordo com Souza e Aires (2020, p. 304): “[...] a Circulação Intercoletiva de Ideias ocorre entre integrantes do mesmo Círculo Esotérico, isto é, o círculo de especialistas de uma área, o qual possui um Estilo de Pensamento próprio, e mantém-se nesse Coletivo de Pensamento, por meio de processos mais ou menos coercitivos".

Como podemos perceber, os artigos apresentam distintas compreensões, tanto para o conceito de circulação intracoletiva, quanto para a circulação intercoletiva. É importante atentar que os autores não fazem uso de citação direta ou mesmo indireta dos escritos de Fleck a esse respeito, diferentemente do que acontece nos conceitos analisados anteriormente. Isso se dá em razão de que as definições de circulação intracoletiva e intercoletiva não são expostas de forma pontual e objetiva por Fleck em seu livro (1986a, 2010), o que contribui para o surgimento de diferentes interpretações e desvios de significados desses conceitos (para usar a própria terminologia de Fleck...).

Constatamos que a compreensão de circulação intracoletiva como comunicação entre os membros de um mesmo coletivo foi a mais encontrada, figurando em 14 artigos. Esse entendimento abrange tanto as comunicações eso-eso, quanto às comunicações eso-exo, ou seja, tudo que é interno a um coletivo de pensamento.

Por outro lado, um número menor de artigos (2) descreve a circulação intracoletiva apenas como uma comunicação entre os círculos eso-exo, ou melhor, uma circulação de ideias entre os especialistas e os leigos. Este entendimento está presente, por exemplo, no seguinte trecho da obra de Fleck, que faz referência a um "estilo de pensamento da moda":

Os adeptos mais fiéis da moda se encontram amplamente no círculo exotérico. Não têm contato imediato com os ditadores poderosos do círculo esotérico. Apenas, por assim dizer, as "criações" específicas chegam até eles, pelas vias oficiais do tráfego intracoletivo, de maneira despersonalizada e mais coercitiva (FLECK, 2010, p. 159-160). 
É importante assinalar que o trecho citado aponta para a circulação intracoletiva entre os círculos eso e exo, mas não exclusivamente. A comunicação eso-eso e exo-exo, dentro de um mesmo EP, também se configura, a nosso ver, como circulação intracoletiva.

A definição de circulação intracoletiva como uma circulação apenas dentro do círculo esotérico, ou seja, entre os especialistas, é encontrada em 3 artigos: Queirós, Nardi e Delizoicov (2014), Gonçalves e Marques (2012a) e Gonçalves e Marques (2012b). Ressaltamos que Gonçalves e Marques (2012b) fundamentam-se no que Delizoicov (2004) elaborou a respeito desse conceito fleckiano, citando-o diretamente:

se a circulação intracoletiva de idéias é, segundo ele [Fleck], responsável pela formação dos pares que compartilharão o estilo de pensamento, quer dizer dos especialistas, no caso de um determinado coletivo de pesquisadores que constituem o que ele denomina de um círculo esotérico. (DELIZOICOV, 2004, p.166 apud GONÇALVES; MARQUES, 2012b, p. 184)

No que concerne à circulação intercoletiva, vimos que 16 artigos a descrevem como uma comunicação de ideias entre coletivos. Esta definição pode estar apoiada, dentre outros, no seguinte trecho de Fleck (2010, p. 162): "Sobre o indivíduo que pertence a várias comunidades de pensamento e que atua como veículo do tráfego intercoletivo de pensamento, há de se dizer ainda [...]". Nesse sentido, podemos pressupor que os indivíduos, como parte do círculo eso ou exo de um coletivo trabalham, através da circulação intracoletiva, reforçando o estilo de pensamento, as ideias e as práticas que lhes são características, e, por outro lado, em posse desses conhecimentos podem propagá-los para outros coletivos, dos quais também fazem parte. Esse contato de um coletivo com as ideias de outro coletivo, a chamada circulação intercoletiva, acontece mediada por indivíduos que atuam como atravessadores de conhecimentos de um coletivo para outro.

Em outros 6 artigos encontramos a descrição de circulação intercoletiva como uma comunicação entre os círculos eso e exotérico, como vimos anteriormente. Parece haver, nesses trabalhos, o entendimento de círculo exotérico como pertencendo a outro coletivo de pensamento. Essa perspectiva justificaria o uso de circulação intercoletiva, ou seja, entre coletivos, para se referir à circulação eso-exo. No entanto, não conseguimos localizar em Fleck (2010) a percepção de círculo exotérico como pertencendo a outro coletivo. Ao contrário, a comunicação entre especialistas e não- 
especialistas não configuraria, necessariamente, circulação de ideias entre EPs distintos, uma vez que os segundos podem se constituir como círculo exo de um mesmo EP em relação aos primeiros.

Por último, nos chamou atenção a definição de circulação intercoletiva dada por Souza e Aires (2020). As autoras descrevem a circulação intercoletiva como uma comunicação no interior do círculo esotérico de um coletivo de pensamento. Esse entendimento revela o quão nebulosa é a interpretação de circulação intercoletiva, que gera não apenas nuances na compreensão, mas extremos desvios de significado, como o encontrado em Souza e Aires (2020).

Conexões ativas e conexões passivas foram os conceitos menos descritos nos artigos, presentes em apenas 7 trabalhos. Por serem dois conceitos que estão intrincados e apareceram, ambos, nos mesmos 7 trabalhos, decidimos expor os resultados em conjunto.

Três trabalhos citam Fleck diretamente. Martins $\left(2020^{a}\right.$, 2020b) cita o seguinte trecho de Fleck (2010, p. 83):

Conhecer, portanto, significa, em primeiro lugar, constatar os resultados inevitáveis sob determinadas condições dadas. Estas condições correspondem aos acoplamentos ativos, formando a parte coletiva do conhecimento. Os resultados inevitáveis equivalem aos acoplamentos passivos e formam aquilo que é percebido como realidade objetiva. $\mathrm{O}$ ato da constatação compete ao indivíduo.

Martins (2020a, p. 1206) complementa: “os acoplamentos ativos representariam aquilo que, grosso modo, é trazido pelo coletivo ao conteúdo do conhecimento. Já os acoplamentos passivos seriam aqueles resultados — ou respostas — 'inevitáveis' e que são percebidos como 'objetivos'”,

Já Scheid, Ferrari e Delizoicov (2007) expressam que as conexões ativas dos sujeitos são mediatizadas tanto pela sua interação com o EP como pela sua interação com o objeto. Os autores citam diretamente o seguinte trecho de Fleck (1986, p. 56 apud SCHEID; FERRARI; DELIZOICOV, p. 160):

Sem dúvida, sempre se encontram no conhecimento cognoscitivo outras conexões que não são explicáveis nem pela história e nem pela psicologia (seja a individual ou coletiva). Justamente por isso parecem relações 'reais', 'objetivas' e 'verdadeiras'. Denominarei estas conexões de passivas, em oposição às que qualificamos de ativas.

Recebido em: 10/02/2021

Aceite em: $11 / 08 / 2021$ 
Outros 3 trabalhos citam Fleck (1986a, 2010) indiretamente. Delizoicov et al. (2002), Tomio e Cassiani (2013) e Queirós, Nardi e Delizoicov (2014) descrevem as conexões ativas como os pressupostos iniciais de um indivíduo sobre um objeto, pressupostos que são condicionados pelo coletivo de pensamento, enquanto as conexões passivas estariam relacionadas às informações que provêm do objeto e que seriam percebidas como "realidade objetiva".

Por último, 1 artigo (SAITO, 2010) cita indiretamente Nogueira (2012, p. 1232). A autora transcreve:

\footnotetext{
Os acoplamentos ativos são resultados de situações consideradas "livremente inventadas", dependentes da escolha do indivíduo, nas quais todas as possibilidades tenderiam ao "subjetivo". Já os acoplamentos passivos são resultado de situações consideradas obrigatoriamente ocorridas, independentemente da escolha do indivíduo, capazes de transmitir a impressão do "real", do "efetivo", onde todas as possibilidades tenderiam ao que se considera como "objetivo".
}

Ao comparar essas descrições, identificamos que os artigos que citam Fleck (1986a, 2010), diretamente ou indiretamente, destacam o papel do coletivo de pensamento na formulação das conexões ativas. Enquanto Saito (2020), que descreve o conceito de conexões ativas através de outro autor, não incorpora essa informação explicitamente na definição, fazendo referência ao indivíduo e não ao grupo.

Nas nossas análises, encontramos uma consonância, em geral, nas compreensões acerca de estilo de pensamento, coletivo de pensamento, círculos esotéricos e círculos exotéricos, tanto através de citações diretas e indiretas da obra de Fleck como por meio da referência a outros autores. Também vimos que, em relação aos conceitos de conexões ativas e conexões passivas, há uma convergência de entendimentos, com apenas uma pequena variação da interpretação. No entanto, quanto à circulação intracoletiva e intercoletiva, encontramos interpretações divergentes.

Quanto à circulação intracoletiva, há um entendimento - minoritário - de que ela estaria restrita à comunicação interna ao círculo eso. Em relação à circulação intercoletiva, identificamos que o entendimento dessa como uma comunicação entre os círculos eso e exotérico encontra-se bastante disseminado, embora não seja a interpretação majoritária. Essas compreensões acerca das circulações intra e inter se reforçam e, de certa forma, se complementam. Observamos que os 3 artigos que 
entendem a circulação intracoletiva como uma comunicação apenas dentro do círculo eso também apresentam a interpretação de circulação intercoletiva como uma comunicação entre os círculos eso e exo.

Conforme apontado anteriormente, consideramos que esses entendimentos não encontram guarida na obra de Fleck, apesar de haver, sem dúvida, possibilidade de compreensões diversas. Quem sabe a observação dos sete artigos de Fleck sobre epistemologia presentes em Cognition and Fact possa lanças algumas luzes quanto a esse quesito. Em particular, mais para o final do artigo de 1947, intitulado To look, to see, to know (FLECK, 1986b, p. 129-151), Fleck trata da circulação intracoletiva quando discute a relação da elite com a massa, para um certo coletivo de pensamento. Está claramente indicado que a comunicação de mão dupla entre elite e massa, situadas em posições diferentes do coletivo, se trata de circulação intracoletiva. Um trecho:

Cada coletivo de pensamento compreende duas classes distintas de membros: a elite e a massa. (...) A massa olha para a elite com uma confiança específica, a elite depende da massa que é portadora da avassaladora "opinião do público em geral". Cada migração intracoletiva do pensamento o fortalece: o leigo aceita a opinião dos especialistas como uma revelação que não deve ser questionada, portanto, a natureza apodítica do enunciado aumenta. Quando o especialista ouve o leigo usar seu pensamento, o do especialista, ele o aceita como uma confirmação, uma vox Dei. Da mesma forma, os leigos entre si ou os especialistas entre si são reconhecidos no estilo de pensamento se descobrem que "meu colega é da mesma opinião". Assim, na migração intracoletiva cada pensamento se fortalece ipso sociologico facto. (FLECK, 1986b, p. 150, tradução nossa, grifos nossos - exceto o último).

Embora Fleck não se utilize, aqui, dos termos 'círculo esotérico' e 'círculo exotérico', claro está que a circulação de ideias eso-eso, exo-exo e eso-exo caem na denominação de circulação intracoletiva.

Concluímos, por fim, que os conceitos de circulação intracoletiva e intercoletiva estão sujeitos a maior variação de entendimentos e desvios de significados.

\section{CONSIDERAÇÕES FINAIS}

Nosso estudo buscou preencher uma lacuna na literatura nacional da área de ensino de ciências no que diz respeito à revisão de trabalhos em periódicos que utilizam a epistemologia de Ludwik Fleck como referencial teórico. Encontramos um total de 32 
artigos publicados no decorrer de vinte anos, com uma maior concentração de publicações nos últimos dez anos.

Observamos, nos trabalhos analisados, a presença de diferentes terminologias para os conceitos circulação de ideias e conexões. Para além das questões que envolvem as dificuldades de tradução da obra de Fleck, tais variações advêm do uso da versão em espanhol (1986) ou do livro em português (2010). Notamos uma preferência pelo uso das terminologias 'circulação' e 'conexões' advindas do livro em espanhol, em detrimento das terminologias 'tráfego' e 'acoplamento' presentes no livro em português.

No que se refere ao uso dos conceitos fleckianos nos artigos, identificamos a predominância na descrição de estilo de pensamento, coletivo de pensamento, círculos esotérico e exotérico, circulação intracoletiva e intercoletiva, com destaque para EP e $\mathrm{CP}$, que surgem na quase totalidade dos trabalhos. Já conexões ativas e passivas são descritas em apenas 7 estudos, ou seja, menos de $25 \%$ do total.

Por fim, observamos que, embora haja pequenas diferenças, há uma consonância na compreensão da maioria dos conceitos fleckianos, o que consideramos refletir uma interpretação fiel da obra de Fleck. Observamos, também, divergências quanto aos entendimentos de circulação intracoletiva e intercoletiva, conceitos para os quais há para ambos - três distintas interpretações. Em relação a essas divergências, consideramos - como apontado no final da seção anterior - um entendimento mais fiel à obra de Fleck a descrição da circulação intracoletiva como sendo qualquer comunicação interna a um coletivo, ou seja, tanto circulações eso-eso, quanto eso-exo e exo-exo. A relação elite-massa situa-se nessa perspectiva. Já a circulação intercoletiva refere-se à comunicação entre coletivos distintos, exclusivamente.

Considerando o crescente interesse por Fleck na área de ensino de ciências, tornase relevante percebermos o modo como sua epistemologia tem sido considerada nessa área de pesquisa, que conceitos são mais utilizados e como são compreendidos. Além disso, todo conjunto de ideias sempre está sujeito a desvios de significado, e identificálos, no caso em questão, pode contribuir para o debate em torno desse referencial teórico.

\section{REFERÊNCIAS}

Recebido em: 10/02/2021

Aceite em: $11 / 08 / 2021$ 
CHICÓRA, T.; AIRES, J. A.; CAMARGO, S. A epistemologia de Ludwik Fleck: análise das produções do encontro nacional de pesquisa em educação em ciências entre os anos 1997 e 2015. ACTIO, Curitiba, v. 3, n. 3, p. 6-25, 2018.

COHEN, R. S.; SCHNELLE, T. Cognition and Fact: Materials on Ludwik Fleck. Dordrecht: D. Reidel Publishing Company, 1986.

DELIZOICOV, D.; CASTILHO, N.; CUTOLO, L. R. A.; DA ROS, M. A.; LIMA, A. M. C. Sociogênese do conhecimento e pesquisa em ensino: contribuições a partir do referencial fleckiano. Caderno Brasileiro de Ensino de Física, Florianópolis, v. 19, número especial, p. 52-69, 2002.

DELIZOICOV, N. C.; CARNEIRO, M. H. S.; DELIZOICOV, D. O movimento do sangue no corpo humano: do contexto da produção do conhecimento para o do seu ensino. Ciência \& educação. Bauru, v. 10, n. 3, p. 443-460, 2004.

FLECK, L. Gênese e desenvolvimento de um fato científico. Belo Horizonte: Fabrefactum, 2010.

FLECK, L. La génesis y el desarrollo de un hecho científico. Alianza Editorial, S. A.; Madrid, 1986a.

FLECK, L. To look, to see, to know. In R. Cohen, \& T. Schnelle (Eds.), Cognition and fact: materials on Ludwik Fleck (pp. 129-151). Dordrecht: Reidel Publish Company, $1986 b$ [original de 1947].

FLÔR, C. C. A história da síntese de elementos transurânicos e extensão da tabela periódica numa perspectiva fleckiana. Química Nova na Escola, v. 31, n. 4, p. 246$250,2009$.

GONÇALVES, F. P.; MARQUES, C. A. A circulação inter e intracoletiva de conhecimento acerca das atividades experimentais no desenvolvimento profissional e na docência de formadores de professores de química. Investigações em Ensino de Ciências, v. 17, n. 2, p. 467-488, 2012a.

GONÇALVES, F. P.; MARQUES, C. A. A circulação inter e intracoletiva de pesquisas e publicações acerca da experimentação no ensino de Química. Revista Brasileira de Pesquisa em Educação em Ciências, v. 12, n. 1, p. 181-204, 2012 b.

GONÇALVES, F. P.; MARQUES, C. A.; DELIZOICOV, D. O desenvolvimento profissional dos formadores de professores de Química: contribuições epistemológicas. Revista Brasileira de Pesquisa em Educação em Ciências, [S. 1.], v. 7, n. 3, 2007. Não paginado

LAMBACH, M.; MARQUES, C. A. Estilos de pensamento de professores de química da Educação de Jovens e Adultos (EJA) do Paraná em processo de formação permanente. Revista Ensaio: pesquisa em educação em ciências, Belo Horizonte, v. 16, n. 01, p. 85-100, 2014a.

Recebido em: 10/02/2021

Aceite em: $11 / 08 / 2021$ 
LAMBACH, M.; MARQUES, C. A. Lavoisier e a influência nos Estilos de Pensamento Químico: contribuições ao ensino de química contextualizado sócio-historicamente.

Revista Brasileira de Pesquisa em Educação em Ciências, [S. 1.], v. 14, n. 1, p. 009030, 2014b.

LANG, S. Conference Report: Ludwik Fleck's theory of thought styles and thought collectives - translations and receptions. Somatosphere, 24 de Junho. 2016.

LORENZETTI, L.; MUENCHEN, C.; SLONGO, I. I. P. A crescente presença da epistemologia de Ludwik Fleck na pesquisa em educação em ciências no Brasil.

Revista Brasileira de Ensino de Ciência e Tecnologia. v. 11, n. 1, p. 373-404, 2018

LORENZETTI, L.; MUENCHEN, C.; SLONGO, I. I. P. A recepção da epistemologia de Fleck pela pesquisa em educação em ciências no Brasil. Ensaio: pesquisa em educação em ciências, Belo Horizonte, v. 15, n. 3, p. 181-197, 2013.

MARCONI, M. de A.; LAKATOS, E. M. Técnicas de pesquisa. 4.ed. São Paulo: Atlas, 2002.

MAGOGA, T. F.; MUENCHEN, C. A abordagem temática na educação em ciências: a caracterização de um estilo de pensamento. Alexandria: Revista de Educação em Ciência e Tecnologia, Florianópolis, v. 11, n. 2, p. 131-157, 2018.

MARTINS, A. F. P. A Obra Aberta de Ludwik Fleck. Revista Brasileira de Pesquisa em Educação em Ciências, [S. l.], v. 20, n. u, p. 1197-1226, 2020a.

MARTINS, A. F. P. Terraplanismo, Ludwik Fleck e o mito de Prometeu. Caderno Brasileiro de Ensino de Física, Florianópolis, v. 37, n. 3, p. 1193-1216, 2020 b.

MILARÉ, T.; REZENDE, D. B. O mundo da necessidade e o processo de construção da pergunta na pesquisa em ensino de química da USP (2006-2009). Alexandria: Revista de Educação em Ciência e Tecnologia, Florianópolis, v. 11, n. 2, p. 307-335, 2018.

MUENCHEN, C.; DELIZOICOV, D. Os três momentos pedagógicos na edição de livros para professores. Ensino de Ciências e Tecnologia em Revista, [S.1.], v. 1, n. 1, p. 84-97, 2011.

OLIVEIRA, R. S.; CEDRAN, J. C.; CORTEZ, J. M.; KIOURANIS, N. M. M.

Mapeando a pesquisa em Ensino de Ciências: um olhar para as linhas de investigação no ENPEC na década de 2010. Revista Insignare Scientia - RIS, v. 4, n. 3, p. 563-581, 3 mar. 2021.

QUEIRÓS, W. P.; NARDI, R.; DELIZOICOV, D. A produção técnico-científica de James Prescott Joule: uma leitura a partir da epistemologia de Ludwik Fleck.

Investigações em Ensino de Ciências, v. 19, n. 1, p. 99-116, 2014.

Recebido em: 10/02/2021

Aceite em: $11 / 08 / 2021$ 
SAITO, M. T. A noção de verdade e a circulação do conhecimento científico em Fleck: elementos para uma reflexão sobre a era da pós-verdade. Caderno Brasileiro de Ensino de Física. v. 37, n. 3, p. 1217-1249, 2020.

SCHEID, N. M. J.; FERRARI, N.; DELIZOICOV, D. Concepções sobre a natureza da ciência num curso de ciências biológicas: imagens que dificultam a educação científica. Investigações em Ensino de Ciências, v. 12, n. 2, p 157-181, 2007.

SILVEIRA, C; MIRANDA, A. C. Tendências das pesquisas da Educação do Campo a partir da análise de publicações nos anais do ENPEC. Revista Insignare Scientia RIS, v. 2, n. 2, p. 76-99, set. 2019.

SOUZA, I. L. N.; AIRES, J. A. A construção coletiva sobre as séries infinitas por Leibniz e Newton. Revista Brasileira de Ensino de Ciência e Tecnologia, Ponta Grossa, v. 13, n. 3, p. 300-323, 2020.

TOMIO, D.; CASSIANI, S. Dear Mr. Charles Darwin... dear Mr. Fritz Müller: da correspondência entre o evolucionista e o naturalista indícios para caracterizar a escrita na ciência e no ensino de ciências. Investigações em Ensino de Ciências, v. 18, n. 2, p. 263-281, 2013.

TRENN, T. J. Genesis and development of a scientific fact. Prefácio. In FLECK, L. Chicago: University of Chicago Press. pp. xiii-xix., 1979. 